LA W RENCE LIVERMORE NATIONAL LABORATORY

J. Slavick

October 3, 2012

My Experience at Lawrence Livermore National Laboratory 
This document was prepared as an account of work sponsored by an agency of the United States government. Neither the United States government nor Lawrence Livermore National Security, LLC, nor any of their employees makes any warranty, expressed or implied, or assumes any legal liability or responsibility for the accuracy, completeness, or usefulness of any information, apparatus, product, or process disclosed, or represents that its use would not infringe privately owned rights. Reference herein to any specific commercial product, process, or service by trade name, trademark, manufacturer, or otherwise does not necessarily constitute or imply its endorsement, recommendation, or favoring by the United States government or Lawrence Livermore National Security, LLC. The views and opinions of authors expressed herein do not necessarily state or reflect those of the United States government or Lawrence Livermore National Security, LLC, and shall not be used for advertising or product endorsement purposes.

This work performed under the auspices of the U.S. Department of Energy by Lawrence Livermore National Laboratory under Contract DE-AC52-07NA27344. 
LLNL-TR-587392

Jeff Slavick

August $10^{\text {th }} 2012$

\section{My Experience at Lawrence Livermore National Laboratory}

Before applying for an internship through Department of Homeland Security, I had never heard of Lawrence Livermore National Laboratory. I knew of a few national labs, and had a vague idea of what they were developing. Within my first week at LLNL, I was awestruck by the amazing technology that they have, and what they are currently developing to support the goals of DHS. My internship at Lawrence Livermore National Laboratory was a learning experience on many different levels. Whether it was working on our project or attending seminars, I learned many useful applications of computer science and developed future research interests. To give a summary of my internship experience, I will begin by describing my project under Dr. Labov. Next, I will go over how my project and other parts of the internship have shaped my future research interests. Finally, I will present some areas of research that I think should be considered to help DHS accomplish its mission.

My project involved extracting features from radiation portal monitor data to be used for a machine learning system that determines if vehicles contain nuclear threats. Nuclear threats are radioactive, however, so are many benign materials. Each alarmed vehicle results in trained experts evaluating the radiation alarm and making a call to a teleforensics center if it is believed to be a threat. Time and resources are wasted making calls for vehicles containing benign sources, and sometimes teleforensics is not called for threats. The goal of our project was to improve the accuracy of radiation 
screening to increase threat sensitivity while reducing the false alarm rate. Using measurements from cargo data and modeling of threat objects, we were able to extract features to be put into a training table for a machine learning system. My specific role was to extract statistical features.

The first week of my project began with learning about nuclear radiation. Being a computer science major, my knowledge in physics was limited and I was unfamiliar with nuclear radiation. Dr. Labov gave me a couple papers and a book on radiation detection to familiarize myself with characteristics of nuclear radiation. I also learned of how nuclear materials can be hidden, such as blocking gamma rays with lead. Moreover, Dr. Labov introduced the complications of how benign sources can be mistaken as threats and vice versa.

After introducing the physics that came into play with our project, Dr. Labov gave me an excel sheet that consisted of radiation measurements on cargo data. The data included physical measurements such as the vehicle speed, whether each vehicle was alarmed, and what the determined source of radiation was. I used MATLAB to plot graphs of gamma counts as a function of time and other relationships. This helped us picture the data we would be performing threat injection and feature extraction on.

The graphs I generated helped provide some early analysis on the data we were working with. Our data had some omitted data to protect the privacy of the company that provided it. We were able to use the graphs and other forms of analysis to estimate vehicle dimensions and the location of the portal monitor panels. I also analyzed 
background measurements and compared them with the first four seconds of each vehicle radiation measurement.

Performing this analysis helped us decide which features we would extract for a machine learning classifier. I was assigned the statistical feature extraction, which consisted of taking the unbiased mean, standard deviation, skew, and kurtosis on the count intensity, vehicle location, and gamma energy. These features would serve as details for the machine learning algorithm when deciding if a vehicle contains a threat. These statistics could also be taken with or without the background radiation. When subtracting the estimated background values, we had to make the decision of whether to allow for "negative counts." I generated graphs for each statistic showing the statistical value in relation to how much background radiation was subtracted beforehand. I compared these results to when we allowed negative counts and when we changed all negative count values to zero.

I extracted these features from the original data that we were given, as well as other data that had been manipulated by another intern. I also used another intern's estimated background template to subtract background from the radiation measurements before I extracted some of the features. Together, the three of us provided 66 features to be assembled into a training table. This training table was sent to Carnegie Mellon University's machine learning system. CMU promptly returned results of the accuracy of their machine learning classification when it used our features, and how much each feature was used in its decision making. 
While working on feature extraction, we had a side project called the "LLNL multisensor roadside measurement campaign." This was an opportunity for us to test radiation equipment similar to the portal monitors that we were extracting features for. We set aside a date to meet with other employees in Global Security to run some trials on the equipment, with multiple vehicles containing a radiation source. The goal of this project was to test and analyze the radiation sensors' ability to detect radiation sources in different vehicles, at varying speeds, and with multiple methods of hiding the radiation sources.

There were several measurements to keep track of during these trials. Vehicle speed, location of radiation source in the vehicle, the method of hiding the source, and details of the source such as the isotope and activity had to be recorded. Some of the trials had multiple vehicles driving in different directions. My role was to record some of these measurements in excel, particularly the starting times that were associated with each vehicle. This served as the first recording in a campaign of multiple trials that will be run on the equipment.

Overall, I learned a lot from my project at LLNL. I felt that after completing the project, I had a firm understanding of how machine learning works. It was also a great opportunity for coding experience. Dr. Labov stressed the importance of writing code so that it was generic and reusable, so that functions that I wrote could be used not only for our project, but in the future for statistical feature extraction. It was also a chance to apply my knowledge of computer science to a field outside of what I usually study. It was a great learning experience and will have a major impact on the remainder of my academic career. 
Before my internship at Lawrence Livermore National Laboratory, I was unsure of whether I wanted to pursue a master's degree, and if I wanted a future career in research. After working on a project with machine learning, I realized the infinite possibilities for its application in today's technology. My internship at LLNL provided an opportunity for my first research experience, and exposed me to many other areas of research that I didn't even know existed. I also attended many seminars and tours of LLNL's facilities, and realized a world of uprising technology that I wanted to be a part of. As I saw each seminar and presentation, I thought of ways in which machine learning technology could be used for them.

One seminar that I particularly liked was called "An Eye on Nuclear North Korea." It was essentially a talk describing the nuclear capabilities of North Korea. The speaker shared of his visits to North Korea's nuclear labs and incidents when the U.S. discovered them creating nuclear weapons. This was done by U.S. scientists analyzing parts from their labs for sources of enriched uranium and other nuclear weapon isotopes. Similar to our project, this consisted of separating benign sources from threats, which can be done with a machine learning classification system. This seminar was both an eye opener to the nuclear threats of other countries and a spark to my interest in machine learning research.

The seminar I found most interesting was called "Cyber, Space, and Intelligence." The presenter talked about issues in cyberspace, such as theft of information over the internet. The presenter discussed the increase of external threats over cyberspace, such as viruses designed for espionage and sabotage. As I watched this seminar, I thought of the possible application for machine learning. After doing 
some background reading, I saw that machine learning can be used to monitor computer networks, and recognize suspicious activity such as viruses. This has inspired an interest for me to conduct research in cyber security. More background reading showed how complex of a research area cyber security is, and has made me consider getting a master's degree in this area.

Before my internship with DHS, I had heard the phrase "machine learning" only a few times, and had a vague understanding of what it was. I did not realize how powerful its implications are and the growing number of technologies using it. The seminars at Lawrence Livermore National Laboratory opened up my eyes to the numerous applications for machine learning in accomplishing Department of Homeland Security's goals. Whether it is used in detecting nuclear threats or monitoring computer networks, I greatly look forward to expanding my knowledge and research in the area of machine learning. I plan on obtaining a master's degree after my undergraduate; I have only to decide whether to concentrate on machine learning or cyber security.

There are an overwhelming number of threats that Department of Homeland Security is protecting us from. My experience at Lawrence Livermore National Laboratory brought many to my attention that I was never aware of. While our country has some of the most cutting edge technology in the world, other countries are only a few steps behind us. While we have done a phenomenal job of keeping our country safe, I still think there are a couple areas of research that should be considered to accomplish the mission and goals of DHS. These two ideas are cyber warfare and developing humanoid soldiers. 
According to President Obama, "Cyber threat is one of the most serious economic and national security challenges we face as a nation." I could not possibly agree more. After attending many seminars, and doing some reading on my own, I noticed this research area for Homeland Security. Whether it is incidents such as hackers coordinating cyber-attacks on the U.S. gas pipelines, or the uprising of another malware similar to Flame, cyber warfare poses as a major threat. I believe this area of research deserves the utmost attention, and can be used as defense as well as offense. If we concentrate on this area of research more, we could design cyber weapons to shut down enemies' computer systems to prevent their efforts of developing illegal weapons. I see this as beneficial because it will not only deter countries from developing dangerous weapons, but also keeps soldiers out of danger.

Humanoid soldiers would also be a useful area of research for DHS. This area of technology could decrease the number of soldiers we lose oversea. The idea of replacing soldiers with robots may sound absurd, but I think it could be realistically done in the foreseeable future. Idaho National Laboratory and Pacific Northwest National Laboratory already have developments in this area, and I think this is something that should be greatly pursued. If equipped with ground penetrating radar and sensors for hundreds of other threats, these humanoid soldiers could outperform humans, and eliminate the loss of soldiers' lives.

My internship Lawrence Livermore National Laboratory was a life changing experience. It was an opportunity for hands-on experience in my field, whether it was behind the computer or testing actual equipment. I thoroughly enjoyed the opportunity to

\footnotetext{
${ }^{1}$ 1. Whitehouse Fact Sheet, Cybersecurity Legislative Proposal (May 12, 2011).
} 
contribute to and learn more about Homeland Security's goals. It opened my eyes to many new uprising technologies, and has greatly influenced my future research interests. I look forward to conducting more research in machine learning and exploring the area of cyber security. I found it a great privilege to work at Lawrence Livermore National Laboratory, and have intentions of returning next year. Overall, my internship at Lawrence Livermore National Laboratory was a major learning experience, and I look forward to visiting it again someday.

This work performed under the auspices of the U.S. Department of Energy by Lawrence Livermore National Laboratory under Contract DE-AC52-07NA27344. 